\title{
COVID-19 and cancer: start the resolution!
}

\author{
Chantal Barksdale ${ }^{1,2,3} \cdot$ Franciele C. Kipper ${ }^{1,2,3} \cdot$ Shreya Tripathy $^{1,2,3} \cdot$ Selvakumar Subbian ${ }^{4} \cdot$ Charles N. Serhan $^{5}$. \\ Dipak Panigrahy ${ }^{1,2,3}$
}

Published online: 21 February 2022

(c) The Author(s), under exclusive licence to Springer Science+Business Media, LLC, part of Springer Nature 2022

\begin{abstract}
Coronavirus disease 2019 (COVID-19) due to infection with severe acute respiratory syndrome coronavirus 2 (SARS-CoV-2) has been an ongoing pandemic causing significant morbidity and mortality worldwide. The "cytokine storm" is a critical driving force in severe COVID-19 cases, leading to hyperinflammation, multi-system organ failure, and death. A paradigm shift is emerging in our understanding of the resolution of inflammation from a passive course to an active biochemical process driven by endogenous specialized pro-resolving mediators (SPMs), such as resolvins, protectins, lipoxins, and maresins. SPMs stimulate macrophage-mediated debris clearance and counter pro-inflammatory cytokine production, a process collectively termed as the "resolution of inflammation." Hyperinflammation is not unique to COVID-19 and also occurs in neoplastic conditions, putting individuals with underlying health conditions such as cancer at elevated risk of severe SARSCoV-2 infection. Despite approaches to block systemic inflammation, there are no current therapies designed to stimulate the resolution of inflammation in patients with COVID-19 or cancer. A non-immunosuppressive therapeutic approach that reduces the cytokine storm in patients with COVID-19 and cancer is urgently needed. SPMs are potent immunoresolvent and organ-protective lipid autacoids that stimulate the resolution of inflammation, facilitate clearance of infections, reduce thrombus burden, and promote a return to tissue homeostasis. Targeting endogenous lipid mediators, such as SPMs, offers an entirely novel approach to control SARS-CoV-2 infection and cancer by increasing the body's natural reserve of proresolving mediators without overt toxicity or immunosuppression.
\end{abstract}

Keywords COVID-19 $\cdot$ Cytokine storm $\cdot$ SARS-CoV-2 $\cdot$ Resolution of inflammation

\section{Introduction}

Chantal Barksdale, Franciele C. Kipper, Selvakumar Subbian, Charles N. Serhan and Dipak Panigrahy contributed equally to this commentary.

$\triangle$ Dipak Panigrahy

dpanigra@bidmc.harvard.edu

1 Center for Vascular Biology Research, Beth Israel Deaconess Medical Center, Harvard Medical School, Boston, MA 02215, USA

2 Department of Pathology, Beth Israel Deaconess Medical Center, Harvard Medical School, Boston, MA 02215, USA

3 Cancer Center, Beth Israel Deaconess Medical Center, Harvard Medical School, Boston, MA 02215, USA

4 Public Health Research Institute, New Jersey Medical School, Rutgers University, Newark, NJ 07103, USA

5 Center for Experimental Therapeutics and Reperfusion Injury, Department of Anesthesiology, Perioperative and Pain Medicine, Brigham and Women's Hospital, Harvard Medical School, Boston, MA 02215, USA
Multiple human diseases, including coronavirus disease 2019 (COVID-19) and cancer, are driven by unresolved inflammation [1,2]. Self-limited, acute inflammation, when properly regulated, is a natural host response to injury or invading pathogens that helps restore homeostasis. This coordinated and host-protective process is initiated by the recognition of pathogen-associated molecular patterns (PAMPs) and damage-associated molecular patterns (DAMPs) by host cells. PAMPs are common motifs found within classes of microbes, e.g., severe acute respiratory syndrome coronavirus 2 (SARS-CoV-2), the virus that causes COVID-19, while DAMPs are molecules released following tissue injury from dying or damaged cells, e.g. cancer. PAMPs and DAMPs are both detected by pattern recognition receptors (PRRs), which include Toll-like receptors (TLRs), retinoic acid-inducible gene I (RIG-I)-like receptors, nucleotide-binding 
oligomerization domain (NOD)-like receptors, and C-type lectin receptors, expressed in innate and adaptive immune cells $[3,4]$. Upon PRR activation, signal transduction pathways lead to the activation of transcription factors, including nuclear factor- $\kappa \mathrm{B}(\mathrm{NF}-\kappa \mathrm{B})$, activator protein 1 (AP-1), interferon-regulated genes (IRGs), and CCAAT enhancer-binding protein beta $(\mathrm{C} / \mathrm{EBP} \beta)$, which upregulate gene expression and the synthesis of pro-inflammatory mediators that coordinate the elimination of pathogens and infected or damaged cells. Inflammatory enzymes locally produce arachidonic acid-derived eicosanoids, such as prostaglandins (PG), leukotrienes (LT), and thromboxanes (TX), which mediate the generation of cytokines and chemokines contributing to a "cytokine storm." Together, these eicosanoids and their downstream mediators contribute to the classical symptoms of inflammation [2, 5-8] first documented by Roman doctor Cornelius Celsus in the first century AD, which include redness (rubor), heat (calor), swelling (tumor), and pain (dolor), and later the addition of loss of function (function laesa) by Rudolph Virchow in the nineteenth century AD [9].

Phagocytosis of microbial invaders and cellular debris by macrophages should control and self-limit the acute inflammatory process, thereby allowing the damaged tissue to begin regeneration and return to homeostasis [10]. However, if there is unsuccessful removal of noxious stimuli, macrophages continue to act as antigen-presenting cells for $\mathrm{T}$ cells, turning acute and physiological inflammation into chronic and pathological [11]. Without adequate clearance, inflammasomes can become activated, triggering a macrophage-derived "eicosanoid storm" of endogenously produced lipid mediators that leads to a cytokine storm with the release of pro-inflammatory cytokines and chemokines, inducing a persistent hyperinflammatory state (Fig. 1) [12]. Hence, sustained pathologic inflammation can cause excessive tissue damage and exacerbate the disease state beyond the acute inflammatory response associated with the initial infection or disease itself. This scenario has been observed
Fig. 1 Hyperinflammation in COVID-19 and cancer occurs due to a cascade of events, including the activation of transcription factors, the production of inflammatory enzymes, and the release of eicosanoids and pro-inflammatory cytokines. These mediators enhance ongoing inflammation, contributing to disease progression and tissue destruction. SPMs, including resolvins, protectins, lipoxins, and maresins, exert their pro-resolving and anti-inflammatory effects by stimulating clearance of noxious stimuli (phagocytosis of SARS-CoV-2 and phagocytosis/ efferocytosis of cancer debris), countering the "cytokine storm," and exhibiting antithrombotic properties. Created with BioRender.com

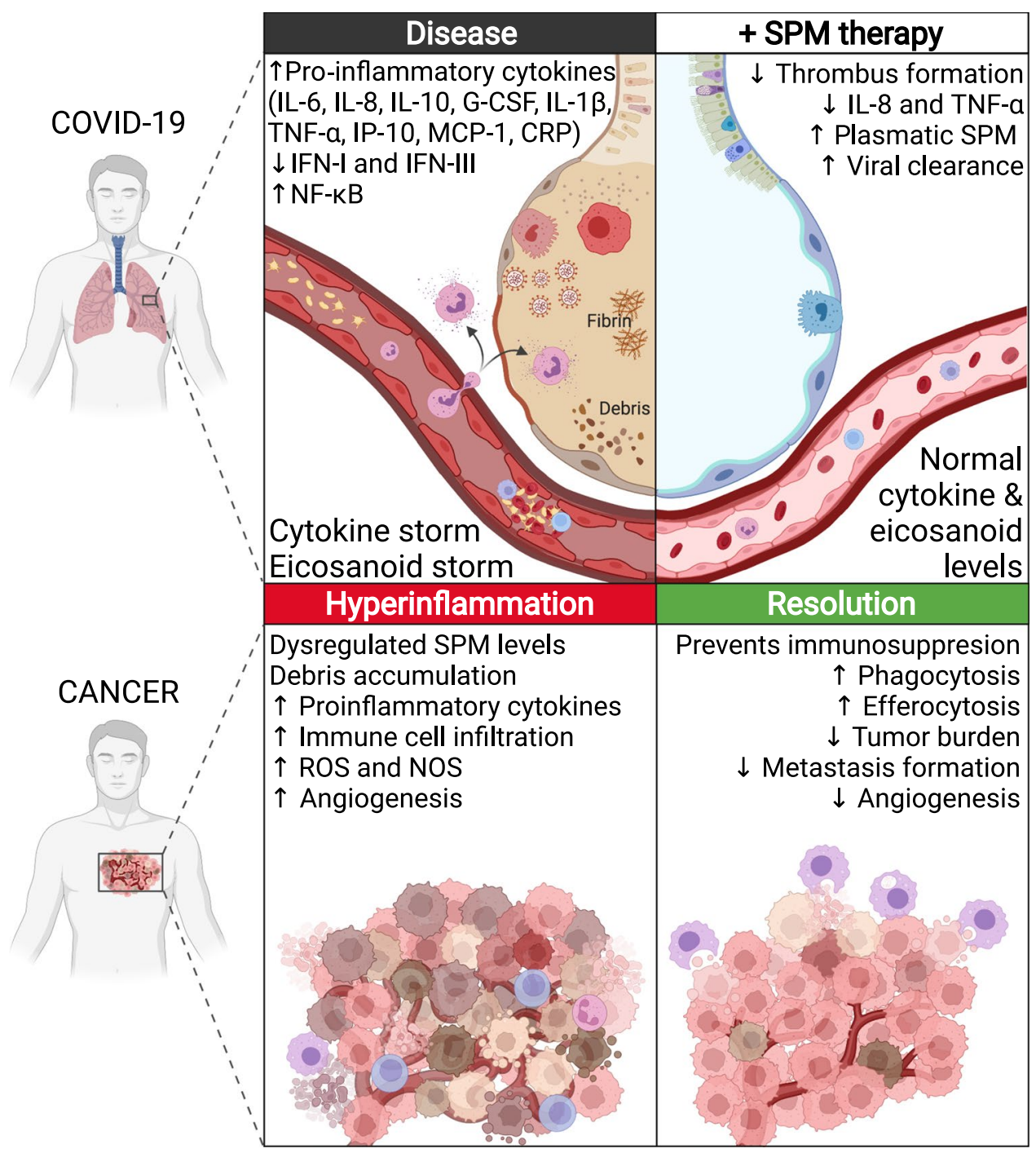


in cancer and COVID-19, both of which have caused widespread morbidity and mortality. Early observations have identified an association between a hyperinflammatory cytokine storm and poor clinical outcomes among patients with COVID-19 [1, 13, 14]. Thus, the pro-inflammatory cytokine storm likely represents a critical driving force in severe COVID-19, potentially leading to sequela such as a systemic inflammatory response and multi-system organ failure in those infected with SARS-CoV-2 [1, 15, 16].

Historically, the resolution of inflammation was considered a passive process, resulting from the loss or dilution of pro-inflammatory mediators from the extracellular milieu [17]. Thus, anti-inflammatory therapies have focused on neutralizing pro-inflammatory mediators, including cytokines, eicosanoids, and their biosynthetic enzymes [18-20]. Despite approaches to block systemic inflammation, there are no current therapies designed to stimulate the resolution of inflammation in patients with COVID-19 or cancer. Although previously believed to be passive, resolution of inflammation is now known to be an active biochemical process orchestrated by lipid autacoids known as specialized pro-resolving mediators (SPMs). SPMs, which include the lipoxin (LX), resolvin (Rv), protectin (PD), and maresin $(\mathrm{MaR})$ families, are biosynthesized from polyunsaturated fatty acids, including arachidonic acid, eicosapentaenoic acid (EPA), docosahexaenoic acid (DHA), and n-3 docosapentaenoic acid [21-23]. Through stereoselective activation of their specific G-protein-coupled receptors (GPCRs), SPMs evoke anti-inflammatory and pro-resolving processes without being immunosuppressive [2, 24]. Professor CN Serhan outlined the basics of the resolution response and mechanisms as well as the potential impact of resolution mediators in tissue regeneration in recent talks to the National Institute of Health (NIH) (https://www.niams.nih. gov/newsroom/featured/inflammation-resolution-round table) and to the National Academies of Sciences, Engineering, and Medicine (https://www.nationalacademies.org/ event/11-02-2021/understanding-the-role-of-the-immunesystem-in-improving-tissue-regeneration-a-workshop). Notably, while some drugs can disrupt timely resolution, aspirin and statins trigger the production of epimeric forms of several SPMs, further promoting the resolution of inflammation [22, 25-30].

Failure to resolve inflammation has been linked to pathologic inflammation in several diseases due to impaired biosynthesis of SPMs, including tuberculous meningitis, multiple sclerosis, and osteoarthritis [31-33]. In fact, within various hyperinflammatory diseases, eicosanoids, SPMs, and SPM/eicosanoid ratios in peripheral blood have been identified as novel serological biomarkers to monitor disease and treatment efficacy [34]. Dysregulated levels of SPMs with elevated eicosanoid patterns (e.g., reduced SPM/ eicosanoid ratio such as resolvin D1/leukotriene $\mathrm{B}_{4}$ ) have been detected in human patients with various inflammatory diseases, including sepsis, chronic obstructive pulmonary disease (COPD), colon cancer, and leukemia [34]. Possible explanations for reduced SPM levels include reduced dietary intake of EPA and DHA as well as mutations in enzymes involved in synthesizing SPMs. Other mechanisms that may also disrupt inflammation resolution include mutations in the genes encoding SPM receptors, diminished expression of SPM receptors, dysfunctional SPM receptors, and abnormal post-SPM receptor intracellular signaling [35, 36]. Failure of resolution, sometimes termed a "resolution deficit," can thus contribute to hyperinflammation in COVID-19 and cancer via uncontrolled eicosanoid and cytokine storms $[13,37,38]$. The direct activity of released cytokines and chemokines in COVID-19 and cancer can cause massive cell death that provokes an ongoing cascade of host responses, including the production of macrophage-derived eicosanoids, that potentiates a vicious cycle of eicosanoid and cytokine storms $[2,39,40]$. Although endogenously produced SPMs exhibit potent inflammation-resolving activities by controlling leukocyte trafficking and countering the production of cytokines and chemokines, absent or diminished SPM levels may allow for ongoing pro-inflammatory processes [2]. Here, building off of a previous review [16], we elucidate parallels between COVID-19 and cancer, highlighting how impaired endogenous pro-resolving pathways may contribute to the hyperinflammation seen in both disease pathologies and offering insight into possible therapeutic interventions moving forward.

\section{Inflammation in COVID-19}

A well-coordinated immune response is critical for defense against viral infections. Hence, dysregulation of the host response can lead to severe tissue damage, exacerbated microbial burden, and progressive disease pathology. The sequela of the inflammatory response that results from SARS-CoV-2 infection can have lasting health complications on patients of all ages, leading to multi-system inflammatory syndrome in children (MIS-C) [41] as well as acute respiratory distress syndrome (ARDS) and multi-system organ failure in adults [42]. The resulting impact on human life has been significant with over five million deaths attributed to COVID-19 globally as of December 2021 [43].

Increased levels of many cytokines and chemokines have previously been demonstrated in humans infected with SARS-associated coronavirus [44-47]. Elevated interleukin 6 (IL-6), IL-10, IL-2 receptor, and tumor necrosis factor alpha (TNF- $\alpha$ ) levels were recently reported in COVID-19 patients and found to correlate with disease severity [48]. Notably, higher plasma levels of IL-2, IL-6, IL-7, IL-10, granulocyte colony-stimulating factor (G-CSF), interferon 
gamma-induced protein 10 (IP-10), monocyte chemoattractant protein-1 (MCP-1), macrophage-inflammatory protein $1 \alpha$ (MIP- $1 \alpha /$ CCL3), and TNF- $\alpha$ were identified in patients with confirmed SARS-CoV-2 infection requiring intensive care $[13,49]$. In one retrospective multi-center study involving 150 hospitalized patients from Wuhan, China, significant differences were identified in plasma levels of inflammatory markers, including IL-6 and C-reactive protein (CRP), between patients who died of COVID-19 versus those discharged [50]. Additionally, increased expression of C-C motif chemokine receptor 5 (CCR5) has been identified in leukocytes of COVID-19 patients compared to healthy controls [51]. These differences suggest that pro-inflammatory mediators can serve as prognostic indicators and should be considered when developing new therapeutic approaches for treating disease complications associated with SARS-CoV-2 infection [50].

Preclinical studies have characterized the inflammatory response resulting from infection with SARS-CoV-2. In animal studies, SARS-CoV-2 has been shown to elicit a strong pro-inflammatory cytokine response after viral infection, culminating in a cytokine storm and reduced pulmonary function associated with lung infiltration by monocytes, neutrophils, and activated T cells [52]. Notably, host response to SARS-CoV-2 infection results in elevated production of chemokines and cytokines, specifically IL-6, while failing to launch a robust interferon (IFN)-I or IFN-III response [53]. Thus, hyperinflammation may result from delayed IFN-I signaling in the presence of rapid SARS-CoV-2 viral replication, allowing for accumulation of pathogenic macrophages, elevated cytokine and chemokine levels, vascular leakage, and impaired T cell responses [54]. Cynomolgus macaques with various clinical conditions and ages infected with SARS-CoV-2 also demonstrated a difference in condition severity between young and older animals with underlying diseases [55]. Despite similar viral loads, the excessive immune response seen in older animals corresponded with more severe lung injury. Of note, it has previously been shown that SARS-CoV-infected aged macaques had an exacerbated innate immune response relative to young adult macaques, which was associated with increased expression of inflammatory genes, such as NF- $\mathrm{\kappa B}$, and reduced expression of IFN-I [56]. In some patients with life-threatening COVID-19 pneumonia, genetic defects at loci involved in the induction and amplification of IFN-I as well as auto-antibodies that neutralize IFN-I were identified [57, 58]. Therapeutic approaches to COVID-19 must therefore account for the hyperinflammatory host response that results from infection with SARS-CoV-2, especially among those with loss of IFNI-dependent immunity [59].

The SARS-CoV spike (S) protein binds to the angiotensinconverting enzyme 2 (ACE2) for viral entry into host cells [60]. The $\mathrm{S}$ protein has been shown to significantly induce endoplasmic reticulum (ER) stress and upregulate early expressed chemokines such as chemokine (C-X-C motif) ligand (CXCL2) in murine models (analogous to human IL-8) [61, 62]. Interestingly, coronavirus infection activates ER stress signaling and induces unfolded protein response (UPR) components at the mRNA level while suppressing them at the protein level [63]. Prolonged ER stress, with the accumulation of unfolded proteins and the consequent induction of UPR, can result in apoptotic cell death and promote an ongoing pro-inflammatory response [64]. Many groups have reported the effect of coronavirus infection on apoptosis over the last decade, and more recently, SARS-CoV-2 has also been shown to induce apoptotic cell death. Ren and collaborators have shown that SARS-CoV-2 ORF3a protein can efficiently induce apoptosis in different cell lines [65, 66]. Altogether, the delayed IFN-I response, increased ER stress, and the subsequent presence of apoptotic cellular debris lead to the development of hyperinflammation via a cytokine storm.

Signaling from cytokines and chemokines serves as an attractant for immune cells, such as neutrophils and macrophages, whose infiltration can result in tissue injury and significant detriment to organs. For example, higher levels of pro-inflammatory cytokines in the urine of patients with COVID-19 have been shown to correlate with kidney tissue damage and acute kidney injury [67]. Other organs impacted by severe COVID-19 include the lungs, heart, spleen, lymph nodes, brain, liver, eyes, vasculature, and skin [68]. In the lungs, differences between moderate and severe COVID-19 cases may result from immune cell extravasation and the presence of non-resident macrophages in the airway epithelium over-expressing cytokines and chemokines. Interestingly, single-cell sequencing analysis revealed stronger interactions between epithelial and immune cells in the airway epithelium of critically ill COVID-19 patients compared to moderate cases, indicated by the profiles of ligand-receptor expression and activated immune cells. The airway epithelium also contained inflammatory macrophages expressing high levels of $\mathrm{C}-\mathrm{C}$ motif chemokine ligand 2 (CCL2), CCL3, CCL20, CXCL1, CXCL3, CXCL10, IL-8, IL-1 $\beta$, and TNF- $\alpha$ [69]. This evidence suggests that a cytokine storm likely explains some of the pathologies associated with severe COVID-19 [1].

A broad array of inflammatory cytokines and chemokines is evident in COVID-19 pathogenesis, i.e., children suffering from MIS-C presented with elevated levels of soluble IL-2 receptor, IL-10, and IL-6 [70]. Thus, efforts to suppress hyperinflammation intrinsic to severe disease should ideally not only target specific inflammatory components but rather aim to resolve inflammation in its entirety. Of note, downregulation of systemic SPM concentrations has been linked with dysregulated phagocyte function and increased disease severity in COVID-19 [71]. Among hospitalized critically 
ill COVID-19 patients, plasma SPMs levels were found to be significantly decreased in those who died of the disease compared to those who were discharged [72]. Therefore, the link between SPM and patient survival suggests that the hyperinflammation present in severe COVID-19 may reflect failed engagement of pro-resolving pathways in inflammation resolution. Thus, rescuing failed resolution may be an ideal approach to treat COVID-19.

\section{Inflammation in cancer}

Inflammation is now a well-recognized hallmark of cancer [73]. While initially believed to be anti-tumoral, the impact of a tumor-associated inflammatory response on tumorigenesis, cancer progression, and metastasis is now appreciated $[73,74]$. At sites of inflammation, phagocytes produce reactive oxygen and nitrogen species that can damage DNA, and chronically inflamed tissues promote cell proliferation, thus multiplying malignant cells [75]. In fact, several inflammatory states have been linked to cancer, such as inflammatory bowel disease and colorectal cancer, bronchitis and lung cancer, and prostatitis and prostate cancer [76]. The infiltration of immune cells into the tumor stroma contributes to an inflammatory milieu similar to that seen in non-neoplastic processes [77], contributing to tumor progression [78-81]. Among recruited inflammatory cells, persistent activation of transcription factors such as NF- $\mathrm{KB}$, signal transducer and activator of transcription 3 (STAT3), and hypoxia-inducible factor $1 \alpha$ (HIF-1 $\alpha)$ results in the production of mediators including cytokines, chemokines, and cyclooxygenase 2 (COX-2) [82]. A pathologic inflammatory cycle continues as the cytokines activate transcription factors in cells, leading to the continual production of inflammatory mediators.

Within this pro-inflammatory milieu, tumor cells can proliferate while circumventing death and invading new tissues by releasing growth factors, survival factors, and proangiogenic factors [39, 83-87]. Several pro-inflammatory mediators, such as TNF- $\alpha$, IL-6, transforming growth factor beta (TGF- $\beta$ ), IL-10, CCL2, and CCL20, have been shown to attract macrophages and participate in both the initiation and progression of cancer $[82,88,89]$. Among in vitro cutaneous melanoma cells, secretion of IL- 1 and TNF- $\alpha$ from macrophages has been shown to upregulate expression of the pro-angiogenic factors IL-8 and vascular endothelial growth factor (VEGF), thus promoting angiogenesis [90].

The cytokine storm is also critical to cancer progression and metastasis. In non-small cell lung cancer patients, elevated IL- 6 and TNF- $\alpha$ levels in tissue and serum samples were associated with metastasis and worsened tumor clinical stage, highlighting the critical role that cytokines play in tumor cell proliferation [91]. On the other hand, IL-1 $\beta$ inhibitors aimed to treat inflammation in myocardial infarction patients led to reduced cancer mortality, reinforcing that proinflammatory IL-1 $\beta$ aids in the progression and invasiveness of cancers [92]. Studies involving murine models have revealed that chemokine receptors also aid in metastasis, as the expression of different receptors results in different metastatic destinations [93]. In mouse models of B16 melanoma, cells overexpressing CCR7 metastasized to lymph nodes, whereas overexpression of CXCR4 increased metastasis to the lungs [94, 95]. Metastasis, however, can be controlled through eicosanoid receptor inhibition, as $\mathrm{PGE}_{2}$ plays a role in suppressing immune responses. In mice deficient in the $\mathrm{PGE}_{2}$ receptor subtype 2 (EP2), lung tumor multiplicity was significantly lower than in wild-type counterparts, suggesting the $\mathrm{PGE}_{2}$ signaling pathway as a potential therapeutic target [96].

Beyond the inflammatory nature of cancer itself, its treatment also can generate debris that further fuels a hyperinflammatory state. Although previously believed to be inert or inhibitory of tumor growth [84, 97], the cellular debris generated by current cancer therapies, including radiation and chemotherapy, can stimulate ongoing inflammation. The Revesz effect, first described in 1956, demonstrates that tumor growth can be stimulated by radiation-induced cell death via an inflammatory response [98]. In fact, co-injection of cell debris with live tumor cells reduces the inoculum of tumor cells needed to produce tumors in animal models [98-100]. Numerous studies have since confirmed that radiation-generated cellular debris drives tumorigenesis and have outlined similar effects from chemotherapy-induced cell death as well, linking this tumorigenesis to a hyperinflammatory state sustained by cytokine storms [99, 101-103]. Moreover, apoptotic cell death has been found to correlate with poor prognosis [104-108]. We recently demonstrated that cellular debris could also stimulate tumor dormancy escape via failure of resolution of inflammation and that resolvins prevent the chemotherapy-induced cytokine storm in cancer models [84]. Thus, a failure of inflammation resolution within cancer permits a sustained hyperinflammatory state, triggering cancer initiation, progression, and metastasis [85]. Given that the balance between pro- and antiinflammatory chemokines and cytokines governs neoplastic growth [88], this highlights the critical need to supplement current treatment practices with therapeutic approaches that counter inflammation and promote its resolution.

\section{Cytokine storm in COVID-19 and cancer}

As outlined above, the cytokine storm is central to the pathogenesis of both COVID-19 and cancer. Additionally, both involve cell death and the generation of cellular debris that can further contribute to the cytokine storm and hyperinflammation. Analyses of the cytokine storm mediators in 
cancer reveal a broad overlap with those observed in the cytokine storm in COVID-19: IL-6, MCP-1, IL-8, TNF $\alpha$, G-CSF, IL-2R, IL-1 $\beta$, IFN- $\gamma$, IP-10, and IL-1 [1, 13, 39, 109]. Thus, therapeutic strategies that promote resolution and work to counter a broad array of inflammatory mediators may be useful in controlling both COVID-19 and cancer.

\section{Traditional approaches to counter inflammation}

With both local and systemic inflammatory responses in COVID-19 and cancer, countering inflammation may be as critical as anti-SARS-CoV-2 or anti-cancer therapies themselves. Efforts to resolve inflammation date back to the ancient Greeks, who postulated that the redness in inflammation was due to an excess of red blood and practiced bloodletting as a means to reduce inflammation [110]. This theory remained in practice into the nineteenth century. Additional attempts to mitigate the pain and fever associated with inflammation were made, including Hippocrates' use of salicylates from willow bark trees in 400 BC [111]. Yet it was not until 1897 that acetyl-salicylic acid (aspirin) was patented by Bayer \& Co.'s chemist Felix Hoffmann [112]. Still, aspirin's exact mechanism of action was not well elucidated until 1971, when Sir John Vane discovered that the inhibition of prostaglandin biosynthesis is the target of aspirin-like drugs [113, 114]. Within the arachidonic pathway, aspirin and non-steroidal anti-inflammatory drugs (NSAIDs) inhibit the activity of COX-1 and COX-2 (except for COX-2-selective NSAIDs like celecoxib), blocking the formation of PGs that cause inflammation, swelling, pain, and fever, therefore providing antipyretic, analgesic, and anti-inflammatory relief [114]. Subsequent therapeutic approaches to suppress inflammation and immune system activation similarly center on the blockade of individual enzymes or mediators rather than attempting to dampen the entire inflammatory response $[85,115]$.

Many current treatments for COVID-19, including steroids, act through anti-inflammatory or immunomodulatory functions without prompting viral clearance [116]. Dexamethasone, a long-acting corticosteroid currently in use for COVID-19 patients requiring supplemental oxygen or ventilatory support, binds to glucocorticoid receptors in the cytoplasm, decreases the expression of proinflammatory cytokines including IL-1, IL-2, IL-6, IL-8, TNF, and IFN- $\gamma$ [117], and suppresses neutrophil migration [118]. One meta-analysis encompassing data from 1,282 critically ill patients demonstrated a lower 28-day all-cause mortality in COVID-19 patients receiving systemic dexamethasone compared to placebo [119]. However, the immunosuppressive nature of glucocorticoids can leave patients vulnerable to secondary bacterial, fungal, or Strongyloides superinfections [120]. Selective cytokine blockade has also been employed against severe COVID-19, including the IL-6 inhibitors tocilizumab [121] and sarilumab [122]. In a fixed-effects meta-analysis that included 10,930 participants from twenty-seven randomized controlled trials, IL-6 antagonists were associated with a lower 28-day mortality among COVID-19 cases compared to placebo (summary OR $0.86,95 \%$ CI $0.79-0.95, p=0.003$ ) [123]. Of note, a large percentage of COVID-19 patients within these trials had secondary infections by 28 days $(21.9 \%$ of patients receiving IL- 6 antagonists versus $17.6 \%$ of patients receiving usual care or placebo) [123]. Despite some success, these antiinflammatory and immunomodulatory therapies leave much room for improvement as patients continue to suffer from profound morbidity due to immunosuppression and risk for secondary infections [124].

Although inflammation is fully recognized as one of the hallmarks of cancer, therapeutic approaches to counter cancer-associated inflammation have yet to be fully implemented despite robust preclinical data [125]. For example, the genetic ablation of COX or PGE synthases has been shown to shift the tumor inflammatory profile toward anti-cancer pathways. Yet therapeutic strategies targeting these mechanisms remain underutilized despite evidence that $\mathrm{PGE}_{2}$ fuels tumor-promoting inflammation that leads to tumor growth in immunocompetent hosts [126]. While NSAIDs are starting to be clinically applied in cancer prevention, including with the US Preventive Services Task Force's recommendations on the use of aspirin to prevent colorectal cancer in adults aged 50 to 59 years, anti-inflammatory strategies are not yet included in the standard of care for anti-cancer regimens [127]. However, one analysis of five randomized controlled trials demonstrated that allocation to aspirin reduced the risk of cancer with distant metastases (hazard ratio $0.64,95 \%$ CI $0.48-0.84, p=0.001$ ), suggesting that patients with cancer may benefit from aspirin and its anti-metastatic properties [128]. Additionally, the intraoperative administration of the NSAID ketorolac demonstrated a statistically significant reduction in the incidence of distant recurrences of breast cancer [129]. Moreover, a significant survival benefit from aspirin use has been observed for patients with esophageal, hepatobiliary, and colorectal cancers [130]. Currently, several clinical trials are underway to characterize the potential survival benefit of aspirin treatment for patients with colorectal cancer [131-134]. In addition, other approaches that target inflammation, such as the inhibition of specific cytokines and chemokines, including IL-1 $\alpha$ (MABp1) and TNF- $\alpha$ (etanercept and infliximab), are showing promising results in preclinical and clinical trials [135-138]. While these findings support the addition of anti-inflammatory therapeutics to standard treatment 
regimens, their success may be limited due to their targeting of specific inflammatory markers rather than system-wide inflammation.

Importantly, multiple side effects and toxicities further confound the benefits of NSAID treatment for patients with cancer. Gastrointestinal complications can be severe, including mucosal ulceration leading to peptic ulcers, reflux esophagitis, and dyspepsia. In fact, aspirin has been shown to increase upper and lower gastrointestinal bleeding risk by $60 \%$ (multivariable hazard ratio $1.62,95 \%$ CI $1.25-2.10$, $p<0.001$ ) in adults aged $\geq 70$ years in the ASPirin in Reducing Events in the Elderly (ASPREE) trial [139]. Furthermore, COX inhibition decreases thromboxane A2 production in platelets, which prolongs bleeding time and disrupts platelet aggregation. Additionally, the shift from the COX to the LOX pathway that occurs with NSAID use can lead to severe bronchoconstriction events in asthmatics [140]. Notably, while selective COX-2 inhibitors, such as celecoxib and rofecoxib, have been shown to prevent colorectal adenomas, their use is not routinely advised due to an increased risk of adverse cardiovascular events [141-143]. Therefore, the use of current anti-inflammatory therapies is complicated by their inability to effectively resolve inflammation as they only target specific components, and by the side effects and adverse events that occur following treatment. Approaches that address the entire pathologic process are urgently needed, especially for hyperinflammatory conditions such as COVID-19 and cancer.

\section{Resolution of inflammation as a new therapeutic target}

While traditional approaches to counter inflammation have focused on utilizing anti-inflammatory mechanisms, a new therapeutic direction involves harnessing the host's endogenous inflammation resolution processes, thereby eradicating the excessive inflammation rather than just dampening one component [144]. Despite some success with anti-inflammatory treatment strategies that target individual enzymes or mediators, hyperinflammatory responses seen in COVID-19, cancer, and other inflammatory diseases may require more comprehensive pharmacologic options that act not only to counter inflammation but also to promote resolution. While dexamethasone has been found to induce DHA-derived SPM production, increasing levels of protectins PD1 and PDX, its immunosuppressive properties have important implications for viral clearance and potential bacterial superinfection, as mentioned above [145, 146]. In addition to many potential adverse events, NSAIDs also indiscriminately inhibit eicosanoid pathways, thereby preventing the production of pro-resolving mediators. Blockade of COX-2 can perpetuate rather than terminate inflammation as prostaglandins play critical roles in pro-resolution processes, including initiating lipid mediator class-switching [147, 148].

Moreover, using traditional anti-inflammatory treatments is further complicated by their inability to clear debris. SPMs, on the other hand, help to orchestrate the return to tissue homeostasis through the clearance of cellular debris by regulating neutrophil infiltration and stimulating efferocytosis through the non-phlogistic recruitment of mononuclear cells $[35,149]$. Since debris is critical to COVID-19 and cancer pathogenesis, it is imperative that SPMs be considered for clinical use in these pathologies. Additionally, given the cytokine storms associated with hyperinflammation in COVID-19 and cancer, it is important to note that SPMs promote inflammation resolution via downregulation of cytokine production by activated CD $8+$ cytotoxic $\mathrm{T}$ cells and CD4 + T helper (Th) 1 and Th17 cells [150]. In preclinical studies focused on cancer, resolvins counter-regulated the macrophage secretion of IL-6, IL-8, CCL4, CCL5, and TNF- $\alpha$ when exposed to chemotherapy-generated cellular debris [84]. Interestingly, a targeted lipidomic analysis of bronchoalveolar lavage (BAL) fluid via tandem mass spectrometry identified an increase in both pro-inflammatory lipid mediators (PGs, LTs, and TX) as well as pro-resolving lipid mediators (Rv D-series, PDX) in severe COVID-19 patients $(n=33)$ compared to healthy controls $(n=25)$ [151]. Similarly, the SARS-CoV-2 virion spike 1 glycoprotein (S1), a component of the spike protein, has been shown to increase chemokine and cytokine release, such as IL- 8 and TNF- $\alpha$, and trigger the biosynthesis of RvD1 in macrophages in vitro [152]. Despite this endogenous SPM production, treatment with RvD1 and RvD2 countered the S1-induced cytokine storm and hyperinflammation by significantly reducing both IL-8 and TNF- $\alpha$ [152], highlighting that an inflammatory milieu that is already producing resolvins may benefit from additional supplementation.

\section{SPMs exhibit anti-viral and anti-thrombotic activities}

SPMs, including RvE1, PD1, and PDX, have shown direct anti-viral activities [153-159]. Protectin D1 markedly attenuated influenza (H5N1) viral replication by inhibiting nuclear export of influenza virus RNA and demonstrated a survival benefit in mice with severe influenza infection [153]. Thus, PD1 effectively restricts influenza replication, even when treatment was initiated 2 days post-viral infection [153, 159]. Moreover, topical RvE1 and PD1 reduced the severity and frequency of herpes simplex virus (HSV)-1-induced inflammatory ocular lesions in murine models by enhancing microbial clearance $[157,158]$. The direct and indirect anti-viral activities of SPMs in various viral diseases in humans and animal models, including the production of anti-viral antibodies and 
the stimulation of lymphocytic activity, highlight their potential use in the treatment of COVID-19 [154-157, 159]. Thus, utilizing SPMs or their precursors in combination with antiviral drugs or vaccines may be a novel, effective, and practical therapeutic approach to combat COVID-19.

Critically, in addition to being anti-viral, SPMs are organprotective and mitigate inflammation-driven lung injury. RvD1, PDX, and MaR1 injected intravenously $8 \mathrm{~h}$ after lipopolysaccharide-induced acute lung injury markedly stimulated alveolar fluid clearance, ultimately resulting in decreased pulmonary edema within an in vivo model [160-162]. Also, in Escherichia coli-induced lung injury, aspirin-triggered (AT) 15-epi-LXA 4 and 17-epi-RvD1 facilitated inflammation resolution by stimulating bacterial clearance and restoring impaired phagocytosis [163]. Lung injury leading to ARDS has dire implications for the morbidity and mortality of patients with COVID-19 [164]; hence, SPMs may represent a novel treatment option given their preclinical success in such inflammatory lung conditions.

In addition to their anti-inflammatory, pro-resolving, and anti-viral properties, SPMs have also been shown to attenuate the severity of pathological thrombosis, providing even more compelling evidence for their use in hypercoagulable conditions like cancer and COVID-19. In a cohort of 62 patients, autopsies demonstrated that patients who died of COVID-19 complications had dysregulated immunothrombosis, evidenced by the presence of neutrophil extracellular traps (NETs) associated with fibrin and platelets, which was not observed in autopsies of non-COVID-19 patients [165]. Moreover, lipid mediator metabololipidomic analysis has demonstrated that RvD1, RvD2, RvD3, RvD5, and RvE1 as well as AT-RvD3 and AT-LXB 4 were absent in patients with coronary artery disease but present in healthy individuals, suggesting that failed local resolution may lead to uncontrolled inflammation and subsequent thrombosis in these patients [166]. Notably, treatment with Lovaza, a pharmacologic preparation of the $n-3$ fatty acids EPA and DHA, resulted in significantly higher levels of combined ATRvD3, RvD6, AT-PD1, and AT-LXB 4 in patients with coronary artery disease compared to those not receiving Lovaza [166]. SPMs were subsequently shown to significantly increase macrophage phagocytosis of clots by an average of approximately 50\% [166]. Similarly, in a murine model of deep venous thrombosis (DVT), RvD4 significantly reduced thrombus burden and decreased the release of NETs [167].

\section{The application of SPMs in COVID-19 and cancer}

A non-immunosuppressive therapeutic approach is urgently needed to stimulate the resolution of inflammation and reduce the cytokine storm in patients with COVID-19 and cancer. SPMs act selectively by promoting endogenous inflammation resolution, clearing inflammatory exudates, and promoting a return to tissue homeostasis, as demonstrated in many inflammatory disease models. Therefore, SPMs are particularly well-suited for application to treat the hyperinflammation associated with cancer and COVID19 and may also provide an additional benefit of anti-viral and anti-thrombotic activity (Fig. 1). Notably, SPMs act at significantly lower doses compared with conventional antiinflammatory agents and are not immunosuppressive [2].

Risk factors for severe COVID-19 and cancer include comorbidities such as obesity and COPD [168], both of which have been hypothesized to confer more adverse outcomes due to SPM dysregulation or deficiencies [169-171]. Importantly, failure of inflammation resolution can be rescued in humans, as evidenced by the increase in systemic resolvin levels and upregulation of resolvin receptors in women with obesity receiving omega-3 fatty acid supplementation [172]. Similarly, parenteral fish oil emulsions and omega-3 fatty acid supplementations have been proposed to treat critically ill COVID-19 patients since the high contents of SPM precursors EPA and DHA may subsequently aid in controlling the hyperinflammatory cytokine storm [173-176]. A randomized, double-blind, placebo-controlled study showed that oral administration of enriched marine oil increases SPM levels in peripheral blood [177]. Additionally, there is a critical unmet medical need to block the cytokine storm in COVID-19 patients who also require cancer chemotherapy. Establishing new models to investigate cancer therapy-mediated effects on COVID-19 is paramount for identifying new treatment modalities to prevent the cytokine storm with severe COVID-19 in cancer patients receiving cytotoxic cancer therapies. Simultaneously blocking the proinflammatory response and activating endogenous resolution of inflammation programs before cancer therapy may eliminate micrometastases, reduce tumor recurrence, and mitigate the cytokine storm in this patient subset [178].

In addition to SPMs, molecules known as conjugates in tissue regeneration, including maresin conjugates in tissue regeneration (MCTR), protectin conjugates in tissue regeneration (PCTR), and resolvin conjugates in tissue regeneration (RCTR), play a key role in promoting tissue regeneration beyond inflammation resolution [179]. Recent publications have shown that PCTR1 and PD1 are upregulated during respiratory syncytial virus (RSV) pneumonia, with overlapping and distinct mechanisms for PCTR1 and PD1 during the resolution of viral infection and its associated inflammation [180]. Further research is needed to confirm the role of these novel mediators in hyperinflammatory conditions like cancer and COVID-19. Nonetheless, the direct application of SPMs is currently being studied as a therapeutic option for several diseases in humans, including COVID-19 and cancer [181-183]. 
Importantly, SPMs have been in clinical trials for inflammatory diseases, including infantile eczema, asthma, and dry eye disease, highlighting their safety and potential for translation to patients suffering from COVID-19 and cancer [184, 185]. As already mentioned, treatment with SPMs in cancer mouse models has resulted in significant inhibition of tumor growth [84], and the preoperative administration of the NSAID ketorolac with resolvins has been shown to synergistically eradicate the occurrence of micrometastases after primary tumor resection [178]. Currently, plans are in development to begin clinical trials to test RvE1 in solid tumor neoplasms. While the application of SPMs has yet to be further studied in COVID-19, dysregulated lipid mediator profiles in patient sera have been found to differentiate moderate from severe COVID-19 disease [186]. Thus, despite underlying etiological differences between SARS-CoV-2 infection and cancer, the similar pathologic inflammatory response suggests that promoting the resolution of inflammation through the application of SPMs, either by inducing their endogenous production and/or supplementing with exogenous administration, is an underutilized therapeutic option. Through their pro-resolving, anti-inflammatory, anti-viral, and anti-thrombotic properties, SPMs offer an entirely novel approach to control SARS-CoV-2 infection and cancer with limited side effects by increasing the body's natural reserve of pro-resolving mediators.

Acknowledgements The authors are supported by NIH grants including R01GM038765 (to CNS); and the Credit Unions Kids at Heart Team (to DP); the C.J. Buckley Pediatric Brain Tumor Fund (DP).

\section{References}

1. Mehta, P., McAuley, D. F., Brown, M., Sanchez, E., Tattersall, R. S., Manson, J. J., Hlh Across Speciality Collaboration UK. (2020). COVID-19: Consider cytokine storm syndromes and immunosuppression. Lancet, 395(10229), 1033-1034. https:// doi.org/10.1016/S0140-6736(20)30628-0

2. Serhan, C. N. (2014). Pro-resolving lipid mediators are leads for resolution physiology. Nature, 510(7503), 92-101. https://doi. org/10.1038/nature 13479

3. Takeuchi, O., \& Akira, S. (2010). Pattern recognition receptors and inflammation. Cell, 140(6), 805-820. https://doi.org/10. 1016/j.cell.2010.01.022

4. Roh, J. S., \& Sohn, D. H. (2018). Damage-associated molecular patterns in inflammatory diseases. Immune Netw, 18(4), e27. https://doi.org/10.4110/in.2018.18.e27

5. Ricciotti, E., \& FitzGerald, G. A. (2011). Prostaglandins and inflammation. Arteriosclerosis, Thrombosis, and Vascular Biology, 31(5), 986-1000. https://doi.org/10.1161/ATVBAHA.110. 207449

6. Conti, P., Caraffa, A., Gallenga, C. E., Ross, R., Kritas, S. K., Frydas, I., \& Toniato, E. (2020). IL-1 induces throboxane-A2 (TxA2) in COVID-19 causing inflammation and micro-thrombi: Inhibitory effect of the IL-1 receptor antagonist (IL-1Ra). J Biol
Regul Homeost Agents, 34(5), 1623-1627. https://doi.org/10. 23812/20-34-4EDIT-65

7. Pober, J. S., \& Sessa, W. C. (2014). Inflammation and the blood microvascular system. Cold Spring Harbor Perspectives in Biology, 7(1), a016345. https://doi.org/10.1101/cshperspect.a016345

8. Proost, P., Wuyts, A., \& van Damme, J. (1996). The role of chemokines in inflammation. International Journal of Clinical and Laboratory Research, 26(4), 211-223. https://doi.org/10.1007/ BF02602952

9. Schultz, M. (2008). Rudolf Virchow. Emerging Infectious Diseases, 14(9), 1480-1481.

10. Serhan, C. N., Chiang, N., \& Van Dyke, T. E. (2008). Resolving inflammation: Dual anti-inflammatory and pro-resolution lipid mediators. Nature Reviews Immunology, 8(5), 349-361. https:// doi.org/10.1038/nri2294

11. Nathan, C., \& Ding, A. (2010). Nonresolving inflammation. Cell, 140(6), 871-882. https://doi.org/10.1016/j.cell.2010.02.029

12. Fung, S. Y., Yuen, K. S., Ye, Z. W., Chan, C. P., \& Jin, D. Y. (2020). A tug-of-war between severe acute respiratory syndrome coronavirus 2 and host antiviral defence: Lessons from other pathogenic viruses. Emerg Microbes Infect, 9(1), 558-570. https://doi.org/10.1080/22221751.2020.1736644

13. Huang, C., Wang, Y., Li, X., Ren, L., Zhao, J., Hu, Y., \& Cao, B. (2020). Clinical features of patients infected with 2019 novel coronavirus in Wuhan China. Lancet, 395(10223), 497-506. https://doi.org/10.1016/S0140-6736(20)30183-5

14. Pedersen, S. F., \& Ho, Y.-C. (2020). SARS-CoV-2: A storm is raging. The Journal of Clinical Investigation, 130(5), 22022205. https://doi.org/10.1172/JCI137647

15. Ye, Q., Wang, B., \& Mao, J. (2020). The pathogenesis and treatment of the 'Cytokine Storm' in COVID-19. The Journal of Infection, 80(6), 607-613. https://doi.org/10.1016/j.jinf.2020.03.037

16. Panigrahy, D., Gilligan, M. M., Huang, S., Gartung, A., CortesPuch, I., Sime, P. J., \& Hammock, B. D. (2020). Inflammation resolution: A dual-pronged approach to averting cytokine storms in COVID-19? Cancer and Metastasis Reviews, 39(2), 337-340. https://doi.org/10.1007/s10555-020-09889-4

17. Serhan, C. N., \& Savill, J. (2005). Resolution of inflammation: The beginning programs the end. Nature Immunology, 6(12), 1191-1197. https://doi.org/10.1038/ni1276

18. Wang, D., \& Dubois, R. N. (2010). Eicosanoids and cancer. Nature Reviews. Cancer, 10(3), 181-193. https://doi.org/10. 1038/nrc2809

19. Greene, E. R., Huang, S., Serhan, C. N., \& Panigrahy, D. (2011). Regulation of inflammation in cancer by eicosanoids. Prostaglandins \& Other Lipid Mediators, 96(1-4), 27-36. https://doi. org/10.1016/j.prostaglandins.2011.08.004

20. Sulciner, M. L., Gartung, A., Gilligan, M. M., Serhan, C. N., \& Panigrahy, D. (2018). Targeting lipid mediators in cancer biology. Cancer Metastasis Reviews, 37(2-3), 557-572. https://doi. org/10.1007/s10555-018-9754-9

21. Serhan, C. N., Clish, C. B., Brannon, J., Colgan, S. P., Chiang, N., \& Gronert, K. (2000). Novel functional sets of lipidderived mediators with antiinflammatory actions generated from omega-3 fatty acids via cyclooxygenase 2 -nonsteroidal antiinflammatory drugs and transcellular processing. Journal of Experimental Medicine, 192(8), 1197-1204. https://doi.org/10. 1084/jem.192.8.1197

22. Serhan, C. N., Hong, S., Gronert, K., Colgan, S. P., Devchand, P. R., Mirick, G., \& Moussignac, R. L. (2002). Resolvins: A family of bioactive products of omega-3 fatty acid transformation circuits initiated by aspirin treatment that counter proinflammation signals. Journal of Experimental Medicine, 196(8), 1025-1037. https://doi.org/10.1084/jem.20020760

23. Chiang, N., \& Serhan, C. N. (2020). Specialized pro-resolving mediator network: An update on production and actions. 
Essays in Biochemistry, 64(3), 443-462. https://doi.org/10. 1042/EBC20200018

24. Serhan, C. N. (2011). The resolution of inflammation: The devil in the flask and in the details. The FASEB Journal, 25(5), 1441-1448. https://doi.org/10.1096/fj.11-0502ufm

25. Dalli, J., Chiang, N., \& Serhan, C. N. (2015). Elucidation of novel 13-series resolvins that increase with atorvastatin and clear infections. Nature Medicine, 21(9), 1071-1075. https:// doi.org/10.1038/nm.3911

26. Oh, S. F., Pillai, P. S., Recchiuti, A., Yang, R., \& Serhan, C. N. (2011). Pro-resolving actions and stereoselective biosynthesis of $18 \mathrm{~S}$ E-series resolvins in human leukocytes and murine inflammation. The Journal of Clinical Investigation, 121(2), 569-581. https://doi.org/10.1172/JCI42545

27. Bazan, N. G., Eady, T. N., Khoutorova, L., Atkins, K. D., Hong, S., Lu, Y., \& Belayev, L. (2012). Novel aspirin-triggered neuroprotectin D1 attenuates cerebral ischemic injury after experimental stroke. Experimental Neurology, 236(1), 122-130. https://doi.org/10.1016/j.expneurol.2012.04.007

28. Serhan, C. N., Fredman, G., Yang, R., Karamnov, S., Belayev, L. S., Bazan, N. G., \& Petasis, N. A. (2011). Novel proresolving aspirin-triggered DHA pathway. Chemistry \& Biology, 18(8), 976-987. https://doi.org/10.1016/j.chembiol.2011.06. 008

29 Sun, Y. P., Oh, S. F., Uddin, J., Yang, R., Gotlinger, K., Campbell, E., \& Serhan, C. N. (2007). Resolvin D1 and its aspirintriggered 17R epimer Stereochemical assignments, anti-inflammatory properties, and enzymatic inactivation. $J$ Biol Chem, 282(13), 9323-9334. https://doi.org/10.1074/jbc.M609212200

30. Dalli, J., Winkler, J. W., Colas, R. A., Arnardottir, H., Cheng, C. Y., Chiang, N., \& Serhan, C. N. (2013). Resolvin D3 and aspirintriggered resolvin D3 are potent immunoresolvents. Chemistry \& Biology, 20(2), 188-201. https://doi.org/10.1016/j.chembiol. 2012.11.010

31. Colas, R. A., Nhat, L. T. H., Thuong, N. T. T., Gomez, E. A., Ly, L., Thanh, H. H., \& Dalli, J. (2019). Proresolving mediator profiles in cerebrospinal fluid are linked with disease severity and outcome in adults with tuberculous meningitis. The FASEB Journal, 33(11), 13028-13039. https://doi.org/10.1096/f. 20190 1590R

32. Kooij, G., Troletti, C. D., Leuti, A., Norris, P. C., Riley, I., Albanese, M., \& Chiurchiu, V. (2020). Specialized pro-resolving lipid mediators are differentially altered in peripheral blood of patients with multiple sclerosis and attenuate monocyte and blood-brain barrier dysfunction. Haematologica, 105(8), 2056-2070. https:// doi.org/10.3324/haematol.2019.219519

33. Sano, Y., Toyoshima, S., Miki, Y., Taketomi, Y., Ito, M., Lee, H., \& Okayama, Y. (2020). Activation of inflammation and resolution pathways of lipid mediators in synovial fluid from patients with severe rheumatoid arthritis compared with severe osteoarthritis. Asia Pacific Allergy, 10(2), e21. https://doi.org/10.5415/ apallergy.2020.10.e21

34. Serhan, C. N., \& Levy, B. D. (2018). Resolvins in inflammation: Emergence of the pro-resolving superfamily of mediators. The Journal of Clinical Investigation, 128(7), 2657-2669. https://doi. org/10.1172/JCI97943

35. Chiang, N., \& Serhan, C. N. (2017). Structural elucidation and physiologic functions of specialized pro-resolving mediators and their receptors. Molecular Aspects of Medicine, 58, 114-129. https://doi.org/10.1016/j.mam.2017.03.005

36. Serhan, C. N., Brain, S. D., Buckley, C. D., Gilroy, D. W., Haslett, C., O'Neill, L. A., \& Wallace, J. L. (2007). Resolution of inflammation: State of the art, definitions and terms. The FASEB Journal, 21(2), 325-332. https://doi.org/10.1096/fj.06-7227rev

37. Xu, Z., Shi, L., Wang, Y., Zhang, J., Huang, L., Zhang, C., \& Wang, F.-S. (2020). Pathological findings of COVID-19 associated with acute respiratory distress syndrome. The Lancet. Respiratory Medicine, 8(4), 420-422. https://doi.org/10.1016/ S2213-2600(20)30076-X

38. Azkur, A. K., Akdis, M., Azkur, D., Sokolowska, M., van de Veen, W., Brüggen, M.-C., \& Akdis, C. A. (2020). Immune response to SARS-CoV-2 and mechanisms of immunopathological changes in COVID-19. Allergy, 75(7), 1564-1581. https://doi. org/10.1111/all.14364

39. Gartung, A., Yang, J., Sukhatme, V. P., Bielenberg, D. R., Fernandes, D., Chang, J., \& Panigrahy, D. (2019). Suppression of chemotherapy-induced cytokine/lipid mediator surge and ovarian cancer by a dual COX-2/sEH inhibitor. Proceedings of the National Academy of Sciences of the United States of America, 116(5), 1698-1703. https://doi.org/10.1073/pnas.1803999116

40. Fishbein, A., Wang, W., Yang, H., Yang, J., Hallisey, V. M., Deng, J., \& Panigrahy, D. (2020). Resolution of eicosanoid/ cytokine storm prevents carcinogen and inflammation-initiated hepatocellular cancer progression. Proceedings of the National Academy of Sciences of the United States of America, 117(35), 21576-21587. https://doi.org/10.1073/pnas.2007412117

41. Godfred-Cato, S., Bryant, B., Leung, J., Oster, M. E., Conklin, L., Abrams, J., California MIS-C Response Team. (2020). COVID-19-associated multisystem inflammatory syndrome in children - United States, March-July 2020. MMWR. Morbidity and Mortality Weekly Report, 69(32), 1074-1080. https://doi.org/ 10.15585/mmwr.mm6932e2

42. Hue, S., Beldi-Ferchiou, A., Bendib, I., Surenaud, M., Fourati, S., Frapard, T., \& de Prost, N. (2020). Uncontrolled innate and impaired adaptive immune responses in patients with COVID19 acute respiratory distress syndrome. American Journal of Respiratory and Critical Care Medicine, 202(11), 1509-1519. https://doi.org/10.1164/rccm.202005-1885OC

43. WHO Coronavirus (COVID-19) Dashboard. (2021). World Health Organization. Retrieved from https://covid19.who.int/

44. Wong, C. K., Lam, C. W., Wu, A. K., Ip, W. K., Lee, N. L., Chan, I. H., \& Sung, J. J. (2004). Plasma inflammatory cytokines and chemokines in severe acute respiratory syndrome. Clinical and Experimental Immunology, 136(1), 95-103. https://doi.org/10. 1111/j.1365-2249.2004.02415.x

45. Zhang, Y., Li, J., Zhan, Y., Wu, L., Yu, X., Zhang, W., \& Lou, J. (2004). Analysis of serum cytokines in patients with severe acute respiratory syndrome. Infection and Immunity, 72(8), 4410-4415. https://doi.org/10.1128/IAI.72.8.4410-4415.2004

46. Chien, J. Y., Hsueh, P. R., Cheng, W. C., Yu, C. J., \& Yang, P. C. (2006). Temporal changes in cytokine/chemokine profiles and pulmonary involvement in severe acute respiratory syndrome. Respirology, 11(6), 715-722. https://doi.org/10.1111/j.14401843.2006.00942.x

47. Aksakal, A., Kerget, B., Kerget, F., \& Askin, S. (2021). Evaluation of the relationship between macrophage migration inhibitory factor level and clinical course in patients with COVID-19 pneumonia. Journal of Medical Virology, 93(12), 6519-6524. https://doi.org/10.1002/jmv.27189

48. Chen, G., Wu, D., Guo, W., Cao, Y., Huang, D., Wang, H., \& Ning, Q. (2020). Clinical and immunological features of severe and moderate coronavirus disease 2019. Journal of Clinical Investigation, 130(5), 2620-2629. https://doi.org/10.1172/JCI13 7244

49. Sivakorn, C., Dechsanga, J., Jamjumrus, L., Boonnak, K., Schultz, M. J., Dorndorp, A. M., \& Techarang, T. (2021). High mobility group box 1 and interleukin 6 at intensive care unit admission as biomarkers in critically ill COVID-19 patients. American Journal of Tropical Medicine and Hygiene. https:// doi.org/10.4269/ajtmh.21-0165

50. Ruan, Q., Yang, K., Wang, W., Jiang, L., \& Song, J. (2020). Clinical predictors of mortality due to COVID-19 based 
on an analysis of data of 150 patients from Wuhan. China. Intensive Care Med, 46(5), 846-848. https://doi.org/10.1007/ s00134-020-05991-x

51. Cuesta-Llavona, E., Gomez, J., Albaiceta, G. M., Amado-Rodriguez, L., Garcia-Clemente, M., Gutierrez-Rodriguez, J., \& Coto, E. (2021). Variant-genetic and transcript-expression analysis showed a role for the chemokine-receptor CCR5 in COVID19 severity. International Immunopharmacology, 98, 107825. https://doi.org/10.1016/j.intimp.2021.107825

52. Winkler, E. S., Bailey, A. L., Kafai, N. M., Nair, S., McCune, B. T., Yu, J., \& Diamond, M. S. (2020). SARS-CoV-2 infection of human ACE2-transgenic mice causes severe lung inflammation and impaired function. Nature Immunology, 21(11), 1327-1335. https://doi.org/10.1038/s41590-020-0778-2

53. Blanco-Melo D, Nilsson-Payant BE, Liu WC, Uhl S, Hoagland D, Moller R, tenOever BR. (2020). Imbalanced host response to SARS-CoV-2 drives development of COVID-19. Cell, 181(5), 1036-1045 e9. https://doi.org/10.1016/j.cell.2020.04.026

54. Abdelmoaty, M. M., Yeapuri, P., Machhi, J., Olson, K. E., Shahjin, F., Kumar, V., \& Gendelman, H. E. (2021). Defining the innate immune responses for SARS-CoV-2-human macrophage interactions. Frontiers in Immunology, 12, 741502. https://doi. org/10.3389/fimmu.2021.741502

55. Urano, E., Okamura, T., Ono, C., Ueno, S., Nagata, S., Kamada, H., \& Yasutomi, Y. (2021). COVID-19 cynomolgus macaque model reflecting human COVID-19 pathological conditions. Proceedings of the National Academy of Sciences, 118(43), e2104847118. https://doi.org/10.1073/pnas.2104847118

56. Smits, S. L., de Lang, A., van den Brand, J. M., Leijten, L. M., van Ij, W. F., Eijkemans, M. J., \& Haagmans, B. L. (2010). Exacerbated innate host response to SARS-CoV in aged non-human primates. PLoS Pathog, 6(2), e1000756. https://doi.org/10.1371/ journal.ppat.1000756

57. Bastard P, Rosen LB, Zhang Q, Michailidis E, Hoffmann HH, Zhang Y, Casanova JL (2020). Autoantibodies against type I IFNs in patients with life-threatening COVID-19. Science, 370(6515) https://doi.org/10.1126/science.abd4585

58. Zhang Q, Bastard P, Liu Z, Le Pen J, Moncada-Velez M, Chen J, Casanova JL (2020). Inborn errors of type I IFN immunity in patients with life-threatening COVID-19. Science, 370(6515). https://doi.org/10.1126/science.abd4570

59. Ramasamy, S., \& Subbian, S. (2021). Critical determinants of cytokine storm and type i interferon response in COVID19 pathogenesis. Clinical Microbiology Reviews, 34(3), e00299-e320. https://doi.org/10.1128/CMR.00299-20

60. Walls, A. C., Park, Y.-J., Tortorici, M. A., Wall, A., McGuire, A. T., \& Veesler, D. (2020). Structure, function, and antigenicity of the SARS-CoV-2 spike glycoprotein. Cell, 181(2), 281-292.e6. https://doi.org/10.1016/j.cell.2020.02.058

61. Versteeg, G. A., van de Nes, P. S., Bredenbeek, P. J., \& Spaan, W. J. (2007). The coronavirus spike protein induces endoplasmic reticulum stress and upregulation of intracellular chemokine mRNA concentrations. Journal of Virology, 81(20), 1098110990. https://doi.org/10.1128/JVI.01033-07

62. Aoe, T. (2020). Pathological aspects of COVID-19 as a conformational disease and the use of pharmacological chaperones as a potential therapeutic strategy. Frontiers in Pharmacology, 11, 1095. https://doi.org/10.3389/fphar.2020.01095

63. Shaban, M. S., Müller, C., Mayr-Buro, C., Weiser, H., MeierSoelch, J., Albert, B. V., \& Kracht, M. (2021). Multi-level inhibition of coronavirus replication by chemical ER stress. Nature Communications, 12(1), 5536. https://doi.org/10.1038/ s41467-021-25551-1

64. Fung, T. S., Huang, M., \& Liu, D. X. (2014). Coronavirusinduced ER stress response and its involvement in regulation of coronavirus-host interactions. Virus Research, 194, 110-123. https://doi.org/10.1016/j.virusres.2014.09.016

65. Li, S., Zhang, Y., Guan, Z., Li, H., Ye, M., Chen, X., \& Peng, K. (2020). SARS-CoV-2 triggers inflammatory responses and cell death through caspase-8 activation. Signal Transduction and Targeted Therapy, 5(1), 235. https://doi.org/10.1038/ s41392-020-00334-0

66. Ren, Y., Shu, T., Wu, D., Mu, J., Wang, C., Huang, M., \& Zhou, X. (2020). The ORF3a protein of SARS-CoV-2 induces apoptosis in cells. Cellular \& Molecular Immunology, 17(8), 881-883. https://doi.org/10.1038/s41423-020-0485-9

67. Gradin, A., Andersson, H., Luther, T., Anderberg, S. B., Rubertsson, S., Lipcsey, M., \& Hultstrom, M. (2021). Urinary cytokines correlate with acute kidney injury in critically ill COVID-19 patients. Cytokine, 146, 155589. https://doi.org/10.1016/j.cyto. 2021.155589

68. Trypsteen, W., Van Cleemput, J., van Snippenberg, W., Gerlo, S., \& Vandekerckhove, L. (2020). On the whereabouts of SARSCoV-2 in the human body: A systematic review. PLOS Pathogens, 16(10), e1009037. https://doi.org/10.1371/journal.ppat. 1009037

69. Chua, R. L., Lukassen, S., Trump, S., Hennig, B. P., Wendisch, D., Pott, F., \& Eils, R. (2020). COVID-19 severity correlates with airway epithelium-immune cell interactions identified by singlecell analysis. Nature Biotechnology, 38(8), 970-979. https://doi. org/10.1038/s41587-020-0602-4

70. DeBiasi, R. L., Harahsheh, A. S., Srinivasalu, H., Krishnan, A., Sharron, M. P., Parikh, K., Children's National Hospital MISCT. (2021). Multisystem inflammatory syndrome of children: Subphenotypes, risk factors, biomarkers, cytokine profiles, and viral sequencing. Journal of Pediatrics, 237(125-135), e18. https:// doi.org/10.1016/j.jpeds.2021.06.002

71. Koenis, D. S., Beegun, I., Jouvene, C. C., Aguirre, G. A., Souza, P. R., Gonzalez-Nunez, M., \& Dalli, J. (2021). Disrupted resolution mechanisms favor altered phagocyte responses in COVID19. Circulation Research, 129(4), e54-e71. https://doi.org/10. 1161/CIRCRESAHA.121.319142

72. Palmas, F., Clarke, J., Colas, R. A., Gomez, E. A., Keogh, A., Boylan, M., \& Dalli, J. (2021). Dysregulated plasma lipid mediator profiles in critically ill COVID-19 patients. PLOS ONE, 16(8), e0256226. https://doi.org/10.1371/journal.pone.0256226

73. Hanahan, D., \& Weinberg, R. A. (2011). Hallmarks of cancer: The next generation. Cell, 144(5), 646-674. https://doi.org/10. 1016/j.cell.2011.02.013

74. Taniguchi, K., \& Karin, M. (2018). NF-кB, inflammation, immunity and cancer: Coming of age. Nature Reviews Immunology, 18(5), 309-324. https://doi.org/10.1038/nri.2017.142

75. Maeda, H., \& Akaike, T. (1998). Nitric oxide and oxygen radicals in infection, inflammation, and cancer. Biochemistry (Moscow), 63(7), 854-865.

76. Agarwal, S., Reddy, G. V., \& Reddanna, P. (2009). Eicosanoids in inflammation and cancer: The role of COX-2. Expert Review of Clinical Immunology, 5(2), 145-165. https://doi.org/10.1586/ 1744666X.5.2.145

77 Dvorak, H. F. (1986). Tumors: Wounds that do not heal Similarities between tumor stroma generation and wound healing. $N$ Engl J Med, 315(26), 1650-9. https://doi.org/10.1056/NEJM198612 253152606

78. DeNardo, D. G., Andreu, P., \& Coussens, L. M. (2010). Interactions between lymphocytes and myeloid cells regulate pro- versus anti-tumor immunity. Cancer and Metastasis Reviews, 29(2), 309-316. https://doi.org/10.1007/s10555-010-9223-6

79. Grivennikov, S. I., Greten, F. R., \& Karin, M. (2010). Immunity, inflammation, and cancer. Cell, 140(6), 883-899. https://doi.org/ 10.1016/j.cell.2010.01.025 
80. Qian, B. Z., \& Pollard, J. W. (2010). Macrophage diversity enhances tumor progression and metastasis. Cell, 141(1), 39-51. https://doi.org/10.1016/j.cell.2010.03.014

81. Colotta, F., Allavena, P., Sica, A., Garlanda, C., \& Mantovani, A. (2009). Cancer-related inflammation, the seventh hallmark of cancer: Links to genetic instability. Carcinogenesis, 30(7), 1073-1081. https://doi.org/10.1093/carcin/bgp127

82. Mantovani, A., Allavena, P., Sica, A., \& Balkwill, F. (2008). Cancer-related inflammation. Nature, 454(7203), 436-444. https:// doi.org/10.1038/nature07205

83. Chang, J., Bhasin, S. S., Bielenberg, D. R., Sukhatme, V. P., Bhasin, M., Huang, S., \& Panigrahy, D. (2019). Chemotherapygenerated cell debris stimulates colon carcinoma tumor growth via osteopontin. FASEB journal: Official publication of the Federation of American Societies for Experimental Biology, 33(1), 114-125. https://doi.org/10.1096/fj.201800019RR

84. Sulciner, M. L., Serhan, C. N., Gilligan, M. M., Mudge, D. K., Chang, J., Gartung, A., \& Panigrahy, D. (2018). Resolvins suppress tumor growth and enhance cancer therapy. Journal of Experimental Medicine, 215(1), 115-140. https://doi.org/10. 1084/jem.20170681

85. Fishbein, A., Hammock, B. D., Serhan, C. N., \& Panigrahy, D. (2021). Carcinogenesis: Failure of resolution of inflammation? Pharmacology \& Therapeutics, 218, 107670. https://doi.org/10. 1016/j.pharmthera.2020.107670

86. Haak, V. M., Huang, S., \& Panigrahy, D. (2021). Debrisstimulated tumor growth: A Pandora's box? Cancer Metastasis Reviews, 40(3), 791-801. https://doi.org/10.1007/ s10555-021-09998-8

87. Deng, J., Yang, H., Haak, V. M., Yang, J., Kipper, F. C., Barksdale, C., \& Panigrahy, D. (2021). Eicosanoid regulation of debris-stimulated metastasis. Proceedings of the National Academy of Sciences of the United States of America, 118(41), e2107771118. https://doi.org/10.1073/pnas.2107771118

88. Coussens, L. M., \& Werb, Z. (2002). Inflammation and cancer. Nature, 420(6917), 860-867. https://doi.org/10.1038/natur e01322

89. Landskron, G., De la Fuente, M., Thuwajit, P., Thuwajit, C., \& Hermoso, M. A. (2014). Chronic inflammation and cytokines in the tumor microenvironment. Journal of Immunology Research, 2014, 1-19. https://doi.org/10.1155/2014/149185

90. Torisu, H., Ono, M., Kiryu, H., Furue, M., Ohmoto, Y., Nakayama, J., \& Kuwano, M. (2000). Macrophage infiltration correlates with tumor stage and angiogenesis in human malignant melanoma: Possible involvement of TNFalpha and IL-1alpha. International Journal of Cancer, 85(2), 182-188.

91. Shang, G. S., Liu, L., \& Qin, Y. W. (2017). IL-6 and TNF-alpha promote metastasis of lung cancer by inducing epithelial-mesenchymal transition. Oncology Letters, 13(6), 4657-4660. https:// doi.org/10.3892/ol.2017.6048

92. Ridker, P. M., MacFadyen, J. G., Thuren, T., Everett, B. M., Libby, P., Glynn, R. J., Group CT. (2017). Effect of interleukin-1beta inhibition with canakinumab on incident lung cancer in patients with atherosclerosis: Exploratory results from a randomised, double-blind, placebo-controlled trial. Lancet, 390(10105), 1833-1842. https://doi.org/10.1016/S01406736(17)32247-X

93. Zlotnik, A., Burkhardt, A. M., \& Homey, B. (2011). Homeostatic chemokine receptors and organ-specific metastasis. Nature Reviews Immunology, 11(9), 597-606. https://doi.org/10.1038/ nri3049

94. Wiley, H. E., Gonzalez, E. B., Maki, W., Wu, M. T., \& Hwang, S. T. (2001). Expression of CC chemokine receptor-7 and regional lymph node metastasis of B16 murine melanoma. Journal of the National Cancer Institute, 93(21), 1638-1643. https://doi.org/ 10.1093/jnci/93.21.1638
95. Murakami, T., Maki, W., Cardones, A. R., Fang, H., Tun Kyi, A., Nestle, F. O., \& Hwang, S. T. (2002). Expression of CXC chemokine receptor- 4 enhances the pulmonary metastatic potential of murine B16 melanoma cells. Cancer Research, 62(24), 7328-7334.

96. Keith, R. L., Geraci, M. W., Nana-Sinkam, S. P., Breyer, R. M., Hudish, T. M., Meyer, A. M., \& Dwyer-Nield, L. D. (2006). Prostaglandin E2 receptor subtype 2 (EP2) null mice are protected against murine lung tumorigenesis. Anticancer Research, 26(4B), 2857-2861.

97. Bonavita, E., Pelly, V. S., \& Zelenay, S. (2018). Resolving the dark side of therapy-driven cancer cell death. The Journal of Experimental Medicine, 215(1), 9-11. https://doi.org/10.1084/ jem.20172044

98. Revesz, L. (1956). Effect of tumour cells killed by x-rays upon the growth of admixed viable cells. Nature, 178(4547), 13911392. https://doi.org/10.1038/1781391a0

99. Huang, Q., Li, F., Liu, X., Li, W., Shi, W., Liu, F. F., \& Li, C. Y. (2011). Caspase 3-mediated stimulation of tumor cell repopulation during cancer radiotherapy. Nature Medicine, 17(7), 860866. https://doi.org/10.1038/nm.2385

100. Chaurio, R., Janko, C., Schorn, C., Maueröder, C., Bilyy, R., Gaipl, U., \& Munoz, L. E. (2013). UVB-irradiated apoptotic cells induce accelerated growth of co-implanted viable tumor cells in immune competent mice. Autoimmunity, 46(5), 317-322. https:// doi.org/10.3109/08916934.2012.754433

101. Correa, M., Machado, J., Jr., Carneiro, C. R., Pesquero, J. B., Bader, M., Travassos, L. R., \& Jasiulionis, M. G. (2005). Transient inflammatory response induced by apoptotic cells is an important mediator of melanoma cell engraftment and growth. International Journal of Cancer, 114(3), 356-363. https://doi. org/10.1002/ijc.20673

102. Ford, C. A., Petrova, S., Pound, J. D., Voss, J. J., Melville, L., Paterson, M., \& Gregory, C. D. (2015). Oncogenic properties of apoptotic tumor cells in aggressive B cell lymphoma. Current Biology, 25(5), 577-588. https://doi.org/10.1016/j.cub.2014.12. 059

103. Zimmerman, M. A., Huang, Q., Li, F., Liu, X., \& Li, C. Y. (2013). Cell death-stimulated cell proliferation: A tissue regeneration mechanism usurped by tumors during radiotherapy. Semin Radiat Oncol, 23(4), 288-295. https://doi.org/10.1016/j.semra donc.2013.05.003

104. de Jong, J. S., van Diest, P. J., \& Baak, J. P. (2000). Number of apoptotic cells as a prognostic marker in invasive breast cancer. British Journal of Cancer, 82(2), 368-373. https://doi.org/10. 1054/bjoc. 1999.0928

105. Sun, B., Sun, Y., Wang, J., Zhao, X., Wang, X., \& Hao, X. (2006). Extent, relationship and prognostic significance of apoptosis and cell proliferation in synovial sarcoma. European journal of cancer prevention: The official journal of the European Cancer Prevention Organisation (ECP), 15(3), 258-265. https:// doi.org/10.1097/01.cej.0000198896.02185.68

106. Gregory, C. D., \& Pound, J. D. (2011). Cell death in the neighbourhood: Direct microenvironmental effects of apoptosis in normal and neoplastic tissues. The Journal of Pathology, 223(2), 177-194. https://doi.org/10.1002/path.2792

107. Naresh, K. N., Lakshminarayanan, K., Pai, S. A., \& Borges, A. M. (2001). Apoptosis index is a predictor of metastatic phenotype in patients with early stage squamous carcinoma of the tongue: A hypothesis to support this paradoxical association. Cancer, 91(3), 578-584.

108. Jalalinadoushan, M., Peivareh, H., \& Azizzadeh Delshad, A. (2004). Correlation between apoptosis and histological grade of transitional cell carcinoma of urinary bladder. Urology Journal, 1(3), 177-179. 
109. Filippou, P. S., \& Karagiannis, G. S. (2020). Cytokine storm during chemotherapy: A new companion diagnostic emerges? Oncotarget, 11(3), 213-215. https://doi.org/10.18632/oncotarget. 27442

110. Majno G. ; J I. (2004). Cells, tissues and disease: Principles of general pathology (2nd ed.). Oxford University Press.

111. Rainsford, K. D. (2007). Anti-inflammatory drugs in the $21 \mathrm{st}$ century. SubCellular Biochemistry, 42, 3-27. https://doi.org/10. 1007/1-4020-5688-5_1

112. Sneader, W. (2000). The discovery of aspirin: A reappraisal. BMJ, 321(7276), 1591-1594. https://doi.org/10.1136/bmj.321. 7276.1591

113. Vane, J. R. (1971). Inhibition of prostaglandin synthesis as a mechanism of action for aspirin-like drugs. Nature: New Biology, 231(25), 232-235. https://doi.org/10.1038/newbio231232a0

114. Vane, J. R., \& Botting, R. M. (2003). The mechanism of action of aspirin. Thrombosis Research, 110(5-6), 255-258. https://doi. org/10.1016/S0049-3848(03)00379-7

115. Panigrahy, D., Gilligan, M. M., Serhan, C. N., \& Kashfi, K. (2021). Resolution of inflammation: An organizing principle in biology and medicine. Pharmacology \& Therapeutics, 227, 107879. https://doi.org/10.1016/j.pharmthera.2021.107879

116. Ripon, M. A. R., Bhowmik, D. R., Amin, M. T., \& Hossain, M. S. (2021). Role of arachidonic cascade in COVID-19 infection: A review. Prostaglandins \& Other Lipid Mediators, 154, 106539. https://doi.org/10.1016/j.prostaglandins.2021.106539

117. Noreen, S., Maqbool, I., \& Madni, A. (2021). Dexamethasone: Therapeutic potential, risks, and future projection during COVID-19 pandemic. European Journal of Pharmacology, 894, 173854. https://doi.org/10.1016/j.ejphar.2021.173854

118. Zentay, Z., Sharaf, M., Qadir, M., Drafta, D., \& Davidson, D. (1999). Mechanism for dexamethasone inhibition of neutrophil migration upon exposure to lipopolysaccharide in vitro: Role of neutrophil interleukin-8 release. Pediatric Research, 46(4), 406-410. https://doi.org/10.1203/00006450-199910000-00008

119. Group WHOREA for C-19 TW, Sterne, J. A. C., Murthy, S., Diaz, J. V., Slutsky, A. S., Villar, J., \& Marshall, J. C. (2020). Association between administration of systemic corticosteroids and mortality among critically ill patients with COVID-19: A meta-analysis. JAMA, 324(13), 1330-1341. https://doi.org/10. 1001/jama.2020.17023

120. Youssef, J., Novosad, S. A., \& Winthrop, K. L. (2016). Infection risk and safety of corticosteroid use. Rheumatic Disease Clinics of North America, 42(1), 157-176. https://doi.org/10.1016/j.rdc. 2015.08.004

121. Rosas, I. O., Bräu, N., Waters, M., Go, R. C., Hunter, B. D., Bhagani, S., \& Malhotra, A. (2021). Tocilizumab in hospitalized patients with severe Covid-19 pneumonia. New England Journal of Medicine, 384(16), 1503-1516. https://doi.org/10.1056/ NEJMoa2028700

122. Lescure, F.-X., Honda, H., Fowler, R. A., Lazar, J. S., Shi, G., Wung, P., \& Vizcarra, P. (2021). Sarilumab in patients admitted to hospital with severe or critical COVID-19: A randomised, double-blind, placebo-controlled, phase 3 trial. The Lancet Respiratory Medicine, 9(5), 522-532. https://doi.org/10.1016/ S2213-2600(21)00099-0

123. Group W. H. O. R. E. A. for C-19 TW, Shankar-Hari, M., Vale, C. L., Godolphin, P. J., Fisher, D., Higgins, J. P. T., \& Sterne, J. A. C. (2021). Association between administration of IL-6 antagonists and mortality among patients hospitalized for COVID-19: A Meta-analysis. JAMA, 326(6), 499-518. https://doi.org/10.1001/ jama.2021.11330

124. Gopalaswamy, R., \& Subbian, S. (2021). Corticosteroids for COVID-19 therapy: Potential implications on tuberculosis. International Journal of Molecular Sciences, 22(7), 3773. https://doi. org/10.3390/ijms22073773
125. Hou, J., Karin, M., \& Sun, B. (2021). Targeting cancer-promoting inflammation - Have anti-inflammatory therapies come of age? Nature Reviews. Clinical Oncology, 18(5), 261-279. https://doi. org/10.1038/s41571-020-00459-9

126. Zelenay, S., Veen van der, A. G., Bottcher, J. P., Snelgrove, K. J., Rogers, N., Acton, S. E., \& Reis e Sousa, C. (2015). Cyclooxygenase-dependent tumor growth through evasion of immunity. Cell, 162(6), 1257-70. https://doi.org/10.1016/j.cell.2015.08.015

127. Cao, Y., Nishihara, R., Wu, K., Wang, M., Ogino, S., Willett, W. C., \& Chan, A. T. (2016). Population-wide impact of long-term use of aspirin and the risk for cancer. JAMA Oncology, 2(6), 762-769. https://doi.org/10.1001/jamaoncol.2015.6396

128. Rothwell, P. M., Wilson, M., Price, J. F., Belch, J. F., Meade, T. W., \& Mehta, Z. (2012). Effect of daily aspirin on risk of cancer metastasis: A study of incident cancers during randomised controlled trials. Lancet, 379(9826), 1591-1601. https://doi.org/10. 1016/S0140-6736(12)60209-8

129. Desmedt, C., Demicheli, R., Fornili, M., Bachir, I., Duca, M., Viglietti, G., \& Biganzoli, E. (2018). Potential benefit of intraoperative administration of ketorolac on breast cancer recurrence according to the patient's body mass index. Journal of the National Cancer Institute, 110(10), 1115-1122. https://doi.org/ 10.1093/jnci/djy042

130. Frouws, M. A., Bastiaannet, E., Langley, R. E., Chia, W. K., van Herk-Sukel, M. P., Lemmens, V. E., \& Liefers, G. J. (2017). Effect of low-dose aspirin use on survival of patients with gastrointestinal malignancies; an observational study. British Journal of Cancer, 116(3), 405-413. https://doi.org/10.1038/bjc.2016. 425

131. Swiss Group for Clinical Cancer Research. (2021). Adjuvant aspirin treatment in PIK3CA mutated colon cancer patients. A randomized, double-blinded, placebo-controlled, phase III trial (clinical trial registration no. NCT02467582). clinicaltrials.gov. Retrieved from https://clinicaltrials.gov/ct2/show/NCT02467582

132. Martling A (2021). A randomized double-blind placebo-controlled study with ASA treatment in colorectal cancer patients with mutations in the PI3K signaling pathway (clinical trial registration no. NCT02647099). clinicaltrials.gov. Retrieved from https://clinicaltrials.gov/ct2/show/NCT02647099

133. Kuang JCW (2021). Aspirin for dukes C and high risk dukes B colorectal cancers - An international, multi-center, double blind, randomized placebo controlled phase III trial (clinical trial registration no. NCT00565708). clinicaltrials.gov. Retrieved from https://clinicaltrials.gov/ct2/show/NCT00565708

134. GJLiefers. (2021). A phase III double-blind placebo-controlled randomised trial of aspirin on recurrence and survival in colon cancer patients (clinical trial registration no. NCT02301286). clinicaltrials.gov. Retrieved from https://clinicaltrials.gov/ct2/ show/NCT02301286

135. Hong, D. S., Hui, D., Bruera, E., Janku, F., Naing, A., Falchook, G. S., \& Kurzrock, R. (2014). MABp1, a first-in-class true human antibody targeting interleukin-1alpha in refractory cancers: An open-label, phase 1 dose-escalation and expansion study. The lancet Oncology, 15(6), 656-666. https://doi.org/10. 1016/S1470-2045(14)70155-X

136. Hickish, T., Andre, T., Wyrwicz, L., Saunders, M., Sarosiek, T., Kocsis, J., \& de Gramont, A. (2017). MABp1 as a novel antibody treatment for advanced colorectal cancer: A randomised, doubleblind, placebo-controlled, phase 3 study. The lancet Oncology, 18(2), 192-201. https://doi.org/10.1016/S1470-2045(17)30006-2

137. Shirmohammadi, E., Ebrahimi, S.-E.S., Farshchi, A., \& Salimi, M. (2020). The efficacy of etanercept as anti-breast cancer treatment is attenuated by residing macrophages. BMC Cancer, 20(1), 836. https://doi.org/10.1186/s12885-020-07228-y 
138. Huang, D., Xue, J., Li, S., \& Yang, D. (2018). Oxaliplatin and infliximab synergize to induce regression of colon cancer. Oncology Letters, 15(2), 1517-1522. https://doi.org/10.3892/ol.2017. 7468

139. Mahady, S. E., Margolis, K. L., Chan, A., Polekhina, G., Woods, R. L., Wolfe, R., \& McNeil, J. J. (2021). Major GI bleeding in older persons using aspirin: Incidence and risk factors in the ASPREE randomised controlled trial. Gut, 70(4), 717-724. https://doi.org/10.1136/gutjnl-2020-321585

140. Lo, P.-C., Tsai, Y.-T., Lin, S.-K., \& Lai, J.-N. (2016). Risk of asthma exacerbation associated with nonsteroidal anti-inflammatory drugs in childhood asthma: A nationwide population-based cohort study in Taiwan. Medicine, 95(41), e5109. https://doi.org/ 10.1097/MD.0000000000005109

141. Arber, N., Eagle, C. J., Spicak, J., Racz, I., Dite, P., Hajer, J., \& Pre, S. A. P. T. I. (2006). Celecoxib for the prevention of colorectal adenomatous polyps. New England Journal of Medicine, 355(9), 885-895. https://doi.org/10.1056/NEJMoa061652

142. Bertagnolli, M. M., Eagle, C. J., Zauber, A. G., Redston, M., Solomon, S. D., Kim, K., \& Investigators, A. P. C. S. (2006). Celecoxib for the prevention of sporadic colorectal adenomas. New England Journal of Medicine, 355(9), 873-884. https://doi. org/10.1056/NEJMoa061355

143. Baron, J. A., Sandler, R. S., Bresalier, R. S., Quan, H., Riddell, R., Lanas, A., Investigators, A., \& Pprov, T. (2006). A randomized trial of rofecoxib for the chemoprevention of colorectal adenomas. Gastroenterology, 131(6), 1674-82. https://doi.org/ 10.1053/j.gastro.2006.08.079

144. Serhan, C. N. (2017). Treating inflammation and infection in the 21st century: New hints from decoding resolution mediators and mechanisms. The FASEB Journal, 31(4), 1273-1288. https://doi. org/10.1096/fj.201601222R

145. Andreakos, E., Papadaki, M., \& Serhan, C. N. (2021). Dexamethasone, pro-resolving lipid mediators and resolution of inflammation in COVID-19. Allergy, 76(3), 626-628. https://doi.org/10. 1111/all.14595

146. Pyrillou K, Chairakaki AD, Tamvakopoulos C \& Andreakos E (2018) Dexamethasone induces omega3-derived immunoresolvents driving resolution of allergic airway inflammation. $J$ Allergy Clin Immunol, 142(2), 691-695 e4. https://doi.org/10. 1016/j.jaci.2018.04.004

147. Levy, B. D., Clish, C. B., Schmidt, B., Gronert, K., \& Serhan, C. N. (2001). Lipid mediator class switching during acute inflammation: Signals in resolution. Nature Immunology, 2(7), 612-619. https://doi.org/10.1038/89759

148. Sugimoto MA, Sousa LP, Pinho V, Perretti M, \& Teixeira MM (2016). Resolution of inflammation: What controls its onset? Frontiers in Immunology, 7.https://doi.org/10.3389/fimmu.2016. 00160

149. Schwab, J. M., Chiang, N., Arita, M., \& Serhan, C. N. (2007). Resolvin E1 and protectin D1 activate inflammation-resolution programmes. Nature, 447(7146), 869-874. https://doi.org/10. 1038/nature05877

150. Chiurchiu, V., Leuti, A., Dalli, J., Jacobsson, A., Battistini, L., Maccarrone, M., \& Serhan, C. N. (2016). Proresolving lipid mediators resolvin D1, resolvin D2, and maresin 1 are critical in modulating T cell responses. Sci Transl Med, 8(353), 353ra111. https://doi.org/10.1126/scitranslmed.aaf7483

151. Archambault, A. S., Zaid, Y., Rakotoarivelo, V., Turcotte, C., Dore, E., Dubuc, I., \& Flamand, N. (2021). High levels of eicosanoids and docosanoids in the lungs of intubated COVID-19 patients. The FASEB Journal, 35(6), e21666. https://doi.org/10. 1096/fj.202100540R

152. Recchiuti, A., Patruno, S., Mattoscio, D., Isopi, E., Pomilio, A., Lamolinara, A., \& Romano, M. (2021). Resolvin D1 and D2 reduce SARS-CoV-2-induced inflammatory responses in cystic fibrosis macrophages. The FASEB Journal, 35(4), e21441. https://doi.org/10.1096/fj.202001952R

153. Morita, M., Kuba, K., Ichikawa, A., Nakayama, M., Katahira, J., Iwamoto, R., \& Imai, Y. (2013). The lipid mediator protectin D1 inhibits influenza virus replication and improves severe influenza. Cell, 153(1), 112-125. https://doi.org/10.1016/j.cell. 2013.02.027

154. Imai, Y. (2015). Role of omega-3 PUFA-derived mediators, the protectins, in influenza virus infection. Biochimica Et Biophysica Acta, 1851(4), 496-502. https://doi.org/10.1016/j.bbalip. 2015.01.006

155. Tam, V. C., Quehenberger, O., Oshansky, C. M., Suen, R., Armando, A. M., Treuting, P. M., \& Aderem, A. (2013). Lipidomic profiling of influenza infection identifies mediators that induce and resolve inflammation. Cell, 154(1), 213-227. https://doi.org/10.1016/j.cell.2013.05.052

156. Tam, V. C. (2013). Lipidomic profiling of bioactive lipids by mass spectrometry during microbial infections. Seminars in Immunology, 25(3), 240-248. https://doi.org/10.1016/j.smim. 2013.08.006

157. Rajasagi, N. K., Reddy, P. B., Suryawanshi, A., Mulik, S., Gjorstrup, P., \& Rouse, B. T. (2011). Controlling herpes simplex virus-induced ocular inflammatory lesions with the lipidderived mediator resolvin E1. The Journal of Immunology, 186(3), 1735-1746. https://doi.org/10.4049/jimmunol.10034 56

158. Rajasagi, N. K., Reddy, P. B., Mulik, S., Gjorstrup, P., \& Rouse, B. T. (2013). Neuroprotectin D1 reduces the severity of herpes simplex virus-induced corneal immunopathology. Investigative Ophthalmology \& Visual Science, 54(9), 6269-6279. https://doi. org/10.1167/iovs.13-12152

159. Baillie, J. K., \& Digard, P. (2013). Influenza-Time to target the host? The New England Journal of Medicine, 369(2), 191-193. https://doi.org/10.1056/NEJMcibr1304414

160. Wang, Q., Zheng, X., Cheng, Y., Zhang, Y. L., Wen, H. X., Tao, Z., \& Jin, S. W. (2014). Resolvin D1 stimulates alveolar fluid clearance through alveolar epithelial sodium channel, $\mathrm{Na}$, K-ATPase via ALX/cAMP/PI3K pathway in lipopolysaccharideinduced acute lung injury. The Journal of Immunology, 192(8), 3765-3777. https://doi.org/10.4049/jimmunol.1302421

161. Zhuo, X. J., Hao, Y., Cao, F., Yan, S. F., Li, H., Wang, Q., \& Jin, S. W. (2018). Protectin DX increases alveolar fluid clearance in rats with lipopolysaccharide-induced acute lung injury. Experimental \& Molecular Medicine, 50(4), 1-13. https://doi.org/10. 1038/s12276-018-0075-4

162. Zhang, J. L., Zhuo, X. J., Lin, J., Luo, L. C., Ying, W. Y., Xie, X., \& Jin, S. W. (2017). Maresin1 stimulates alveolar fluid clearance through the alveolar epithelial sodium channel $\mathrm{Na}$, K-ATPase via the ALX/PI3K/Nedd4-2 pathway. Laboratory Investigation, 97(5), 543-554. https://doi.org/10.1038/labinvest.2016.150

163. Sekheri, M., El Kebir, D., Edner, N., \& Filep, J. G. (2020). 15-Epi-LXA4 and 17-epi-RvD1 restore TLR9-mediated impaired neutrophil phagocytosis and accelerate resolution of lung inflammation. Proc Natl Acad Sci U S A, 117(14), 7971-7980. https:// doi.org/10.1073/pnas.1920193117

164. Sandhaus, S., \& Swick, A. G. (2021). Specialized proresolving mediators in infection and lung injury. BioFactors, 47(1), 6-18. https://doi.org/10.1002/biof.1691

165. Nicolai, L., Leunig, A., Brambs, S., Kaiser, R., Weinberger, T., Weigand, M., \& Stark, K. (2020). Immunothrombotic dysregulation in COVID-19 pneumonia is associated with respiratory failure and coagulopathy. Circulation, 142(12), 1176-1189. https:// doi.org/10.1161/CIRCULATIONAHA.120.048488

166. Elajami, T. K., Colas, R. A., Dalli, J., Chiang, N., Serhan, C. N., \& Welty, F. K. (2016). Specialized proresolving lipid mediators in patients with coronary artery disease and their potential for 
clot remodeling. The FASEB Journal, 30(8), 2792-2801. https:// doi.org/10.1096/fj.201500155R

167. Cherpokova, D., Jouvene, C. C., Libreros, S., DeRoo, E. P., Chu, L., de la Rosa, X., \& Serhan, C. N. (2019). Resolvin D4 attenuates the severity of pathological thrombosis in mice. Blood, 134(17), 1458-1468. https://doi.org/10.1182/blood.2018886317

168. Figliozzi S, Masci PG, Ahmadi N, Tondi L, Koutli E, Aimo A, Georgiopoulos G (2020). Predictors of adverse prognosis in COVID-19: A systematic review and meta-analysis. European Journal of Clinical Investigation, 50(10). https://doi.org/10.1111/ eci.13362

169. Pal, A., Gowdy, K. M., Oestreich, K. J., Beck, M., \& Shaikh, S. R. (2020). Obesity-driven deficiencies of specialized pro-resolving mediators may drive adverse outcomes during SARS-CoV-2 infection. Frontiers in Immunology, 11, 1997. https://doi.org/10. 3389/fimmu.2020.01997

170. Neuhofer, A., Zeyda, M., Mascher, D., Itariu, B. K., Murano, I., Leitner, L., \& Stulnig, T. M. (2013). Impaired local production of proresolving lipid mediators in obesity and 17-HDHA as a potential treatment for obesity-associated inflammation. Diabetes, 62(6), 1945-1956. https://doi.org/10.2337/db12-0828

171. Croasdell, A., Thatcher, T. H., Kottmann, R. M., Colas, R. A., Dalli, J., Serhan, C. N., \& Phipps, R. P. (2015). Resolvins attenuate inflammation and promote resolution in cigarette smokeexposed human macrophages. American Journal of Physiology. Lung Cellular and Molecular Physiology, 309(8), L888-901. https://doi.org/10.1152/ajplung.00125.2015

172. Polus, A., Zapala, B., Razny, U., Gielicz, A., Kiec-Wilk, B., Malczewska-Malec, M., \& Dembinska-Kiec, A. (2016). Omega-3 fatty acid supplementation influences the whole blood transcriptome in women with obesity, associated with pro-resolving lipid mediator production. Biochimica et Biophysica Acta, 1861(11), 1746-1755. https://doi.org/10.1016/j.bbalip.2016.08.005

173. Torrinhas, R. S., Calder, P. C., Lemos, G. O., \& Waitzberg, D. L. (2021). Parenteral fish oil: An adjuvant pharmacotherapy for coronavirus disease 2019? Nutrition, 81, 110900. https://doi.org/ 10.1016/j.nut.2020.110900

174. Torrinhas, R. S., Calder, P. C., \& Waitzberg, D. L. (2020). Response to Bistrian BR. Parenteral fish-oil emulsions in critically ill COVID-19 emulsions. JPEN J Parenter Enteral Nutr, 44(7), 1169-1170.

175. Rogero, M. M., Leao, M. C., Santana, T. M., Pimentel, M., Carlini, G. C. G., da Silveira, T. F. F., \& Castro, I. A. (2020). Potential benefits and risks of omega-3 fatty acids supplementation to patients with COVID-19. Free Radical Biology \& Medicine, 156, 190-199. https://doi.org/10.1016/j.freeradbiomed.2020.07.005

176. Simopoulos, A. P., Serhan, C. N., \& Bazinet, R. P. (2021). The need for precision nutrition, genetic variation and resolution in Covid-19 patients. Molecular Aspects of Medicine, 77, 100943. https://doi.org/10.1016/j.mam.2021.100943

177. Souza, P. R., Marques, R. M., Gomez, E. A., Colas, R. A., De Matteis, R., Zak, A., \& Dalli, J. (2020). Enriched marine oil supplements increase peripheral blood specialized pro-resolving mediators concentrations and reprogram host immune responses: A randomized double-blind placebo-controlled study. Circulation Research, 126(1), 75-90. https://doi.org/10.1161/CIRCR ESAHA.119.315506

178. Panigrahy, D., Gartung, A., Yang, J., Yang, H., Gilligan, M. M., Sulciner, M. L., \& Sukhatme, V. P. (2019). Preoperative stimulation of resolution and inflammation blockade eradicates micrometastases. The Journal of Clinical Investigation, 129(7), 2964-2979. https://doi.org/10.1172/JCI127282

179. Serhan, C. N., Chiang, N., \& Dalli, J. (2018). New pro-resolving n-3 mediators bridge resolution of infectious inflammation to tissue regeneration. Molecular Aspects of Medicine, 64, 1-17. https://doi.org/10.1016/j.mam.2017.08.002

180. Walker, K. H., Krishnamoorthy, N., Brüggemann, T. R., Shay, A. E., Serhan, C. N., \& Levy, B. D. (2021). Protectins PCTR1 and PD1 reduce viral load and lung inflammation during respiratory syncytial virus infection in mice. Frontiers in Immunology, 12, 704427. https://doi.org/10.3389/fimmu.2021.704427

181. Lee, C. H. (2021). Role of specialized pro-resolving lipid mediators and their receptors in virus infection: A promising therapeutic strategy for SARS-CoV-2 cytokine storm. Archives of Pharmacal Research, 44(1), 84-98. https://doi.org/10.1007/ s12272-020-01299-y

182. Sousa, L. P., Pinho, V., \& Teixeira, M. M. (2020). Harnessing inflammation resolving-based therapeutic agents to treat pulmonary viral infections: What can the future offer to COVID-19? British Journal of Pharmacology, 177(17), 3898-3904. https:// doi.org/10.1111/bph.15164

183. Balta, M. G., Papathanasiou, E., \& Christopoulos, P. F. (2021). Specialized pro-resolving mediators as potential regulators of inflammatory macrophage responses in COVID-19. Frontiers in Immunology, 12, 632238. https://doi.org/10.3389/fimmu.2021. 632238

184. Wu, S. H., Chen, X. Q., Liu, B., Wu, H. J., \& Dong, L. (2013). Efficacy and safety of 15(R/S)-methyl-lipoxin A(4) in topical treatment of infantile eczema. British Journal of Dermatology, 168(1), 172-178. https://doi.org/10.1111/j.1365-2133.2012. 11177.x

185. Christie, P. E., Spur, B. W., \& Lee, T. H. (1992). The effects of lipoxin A4 on airway responses in asthmatic subjects. The American Review of Respiratory Disease, 145(6), 1281-1284. https://doi.org/10.1164/ajrccm/145.6.1281

186. Schwarz B, Sharma L, Roberts L, Peng X, Bermejo S, Leighton I, Bosio CM (2020). Severe SARS-CoV-2 infection in humans is defined by a shift in the serum lipidome resulting in dysregulation of eicosanoid immune mediators. Res $S q$. https://doi.org/10. 21203/rs.3.rs-42999/v1

Publisher's Note Springer Nature remains neutral with regard to jurisdictional claims in published maps and institutional affiliations. 